\title{
AVALIAÇÃO DE MEIOS FILTRANTES PRIMÁRIOS EM FILTRO CONTÍNUO DE TAMBOR ROTATIVO A VÁCUO PARA LODO DE CALDO DE CANA
}

\author{
WALTER L. POLONIO ${ }^{1}$, ELIETE M. GONÇALVES ${ }^{2}$, PAULO C. RAZUK ${ }^{3}$
}

RESUMO: Este estudo teve o objetivo de avaliar o comportamento de treze tipos de meios filtrantes primários desenvolvidos para uso na filtração a vácuo de lodo de caldo de cana, simulando as operações de formação e desidratação da torta em filtros contínuos de tambor rotativo a vácuo, empregados nas indústrias de açúcar e álcool do Brasil. Para tanto, foi desenvolvida uma planta-piloto anexa ao filtro de tambor rotativo a vácuo, na qual foram realizados todos os ensaios, com o objetivo de refletir a realidade das variáveis operacionais durante uma safra sucroalcooleira. Os resultados são apresentados, comparando-se as taxas de filtração, variando a pressão de formação da torta, temperatura e concentração de auxiliar filtrante, mostrando ao usuário um novo caminho para o melhoramento quantitativo e qualitativo, sem aumentar a área nominal da unidade de filtração.

PALAVRAS-CHAVE: chapa perfurada, filtração a vácuo, indústria sucroalcooleira.

\section{EVALUATION OF PRIMARY FILTERING MEDIA IN ROTARY VACUUM DRUM FILTERS FOR SUGAR-CANE MUD}

ABSTRACT: This study aimed to evaluate the behavior or thirteen primary filtering media developed for to use in vacuum filtration of sugar-cane mud, simulating the formation and dewatering operations of the cake in Rotary Vacuum Drum Filters, applied in Sugar and Alcohol Mills in Brazil. For such, a pilot plant was attached to the Rotary Vacuum Drum Filter where all the essays took place, aiming to reflect the reality of the operation variables along the sugar and alcohol harvest. The results are shown with the comparison of filtration indexes, varying the cake formation pressure, the temperature and the concentration of the filtering auxiliary, giving the user a new way for quantitative and qualitative improvement, without the need to increase the nominal area of the filtering unity.

KEYWORDS: filter media, perforated sheet, sugar and alcohol industry.

\section{INTRODUÇÃO}

Filtros contínuos de tambor rotativo a vácuo são os equipamentos mais utilizados na indústria sucroalcooleira no Brasil, em função do tipo de tratamento utilizado na clarificação do caldo de cana, que é a sulfitação. Estima-se que, para a produção nacional de 320 milhões de toneladas de cana-deaçúcar (CATANDUVA \& CIQUEIRA, 1999), sejam necessários $51.850 \mathrm{~m}^{2}$ de área filtrante, mantendo a relação média de $0,7 \mathrm{~m}^{2}$ de área de filtração por tonelada de cana moída por hora, com período médio de duração da safra de 180 dias.

Segundo ARQUED (1955), o primeiro filtro de tambor rotativo a vácuo foi instalado no Brasil nas usinas de açúcar e álcool, em 1927, pelo fabricante Oliver Campbell. SPENCER \& MEADE (1967) citam que os filtros de tambor rotativos a vácuo substituíram rapidamente os filtros-prensa, a partir de 1935. Os diferentes tipos de equipamentos para filtração de lodo buscam melhor eficiência da filtração, com a elevação dos índices de retenção de sólidos. Recentemente, o setor sucroalcooleiro tem investido em instalação de filtros contínuos do tipo correia, na busca de melhor eficiência, sem

\footnotetext{
${ }^{1}$ Eng ${ }^{\mathrm{o}}$ Mecânico, Mestrando em Equipamentos e Processos Industriais, Faculdade de Engenharia, UNESP, Câmpus de Bauru - SP, Fone: (0XX14) 3604.4612, Fax: (0XX14) 3604.4603, polonio@ netsite.com.br.

${ }^{2}$ Prof $^{\text {at }}$. Dr ${ }^{\mathrm{a}}$., Departamento de Matemática, Faculdade de Ciências, UNESP - Câmpus de Bauru - SP.

${ }^{3}$ Prof. Titular, Departamento de Engenharia Mecânica, Faculdade de Engenharia, UNESP - Câmpus de Bauru - SP.

Recebido pelo Conselho Editorial em: 4-8-2003

Aprovado pelo Conselho Editorial em: 2-12-2005
} 
mesmo ter otimizado as variáveis físicas do filtro contínuo de tambor rotativo a vácuo, como exemplo, o meio filtrante primário.

PERRY et al. (1977) relatam que filtros contínuos de tambor rotativo a vácuo processam mais toneladas de sólidos do que qualquer outro tipo de filtro combinado, o que permanece até hoje. Outros setores que utilizam filtros de tambor rotativo a vácuo, como mineração, possuem melhor controle das variáveis físicas do equipamento.

O objetivo do presente trabalho é comparar treze tipos de meios filtrantes primários, com o padrão mais utilizado na quase totalidade das usinas sucroalcooleiras, através das taxas de filtração obtidas.

\section{MATERIAL E MÉTODOS}

O experimento foi realizado no setor de filtração de lodo de caldo de cana da Usina da Barra S.A. - Açúcar e Álcool, em Barra Bonita - SP. Foi desenvolvida e construída uma planta-piloto e instalada anexa a um filtro de tambor rotativo com diâmetro de $4.267 \mathrm{~mm}$ por $12.192 \mathrm{~mm}$ de largura. Uma rede de vácuo instalada na planta-piloto e na alimentação de lodo de caldo de cana diretamente da bacia do real filtro a vácuo garantia que todas as variáveis do processo envolvidas no decorrer de toda a safra canavieira pudessem ser avalizadas. Um dispositivo de filtração denominado "TesteFolha" foi projetado para avaliação em área calibrada dos elementos filtrantes primários em teste.

Os trabalhos foram iniciados a partir de testes com 13 elementos filtrantes primários descritos na Tabela 1, com água à temperatura controlada, variando os níveis de vácuo. Numa segunda etapa, realizaram-se os ensaios com o lodo de caldo de cana durante o período decorrente de uma safra (210 dias), abrangendo, dessa forma, todas as variáveis sazonais. Numa terceira fase, foram realizados ensaios com variação de temperatura, níveis de vácuo e concentração de auxiliar filtrante.

TABELA 1. Resumo dos meios filtrantes primários testados (chapas perfuradas e perfis trapezoidais).

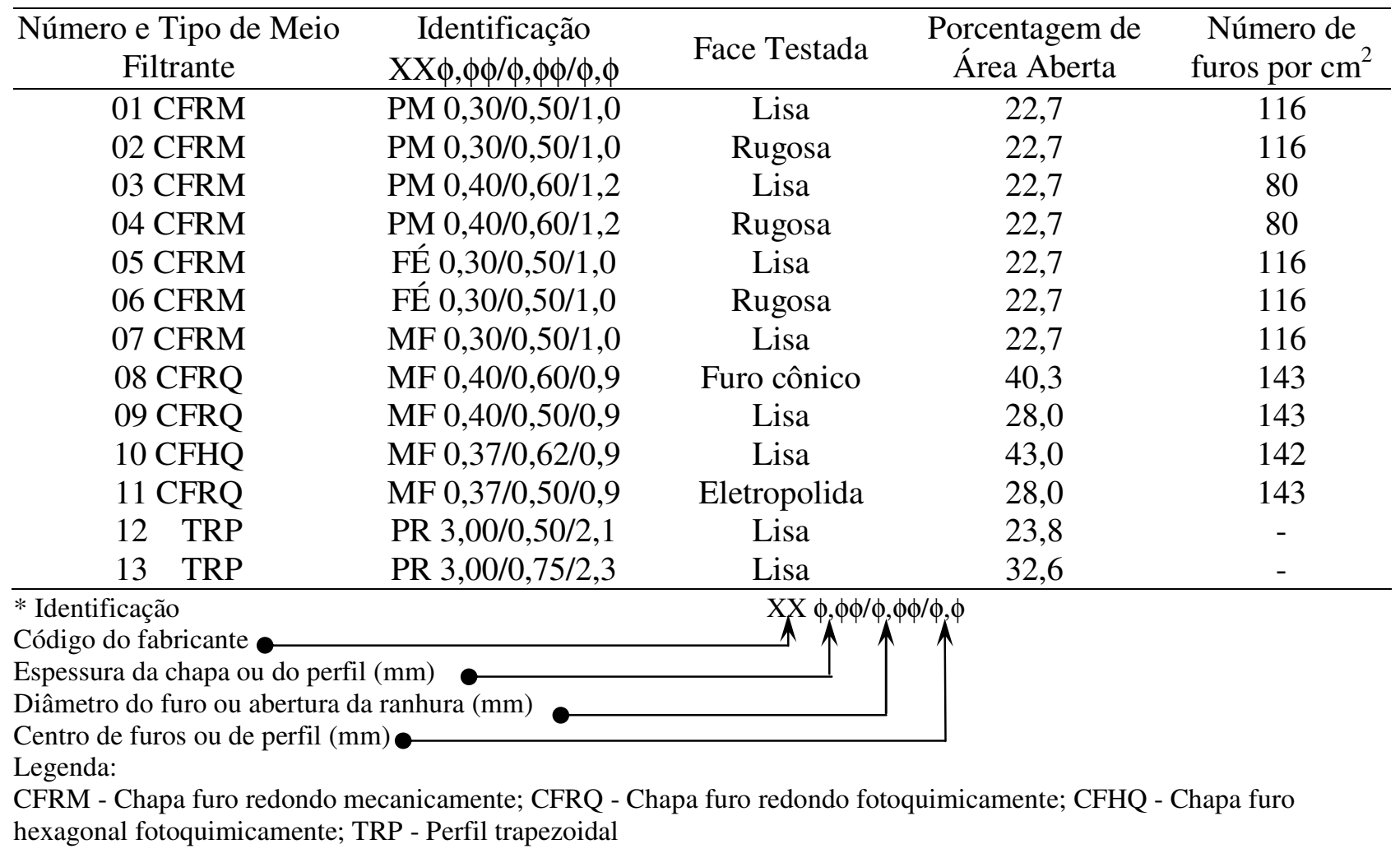


Os volumes coletados das partes separadas do lodo, respectivamente, caldo filtrado e parte sólida (torta), foram quantificados para cada ciclo de ensaio. Assim, as taxas de filtração e as variáveis do processo foram obtidas. As análises do lodo dessecado pela filtração com a geração de torta e dos filtrados foram feitas no próprio laboratório da Usina da Barra.

\section{Aparatos do teste-folha}

O 'típico' teste-folha é um disco circular com área plana de $9.290 \mathrm{~mm}^{2}$, que equivale ao diâmetro de 108,8 $\mathrm{mm}$. Uma face da folha é encaixada para prover grande escoamento de parte do filtrado em um suporte para o meio filtrante primário. Um conector de drenagem, com diâmetro de $9,5 \mathrm{~mm}$, está instalado na outra face da folha. O teste-folha é ajustado com um meio filtrante primário e uma cinta de metal circular e fixado por uma abraçadeira, e a montagem fixa ambos (Figura 1).

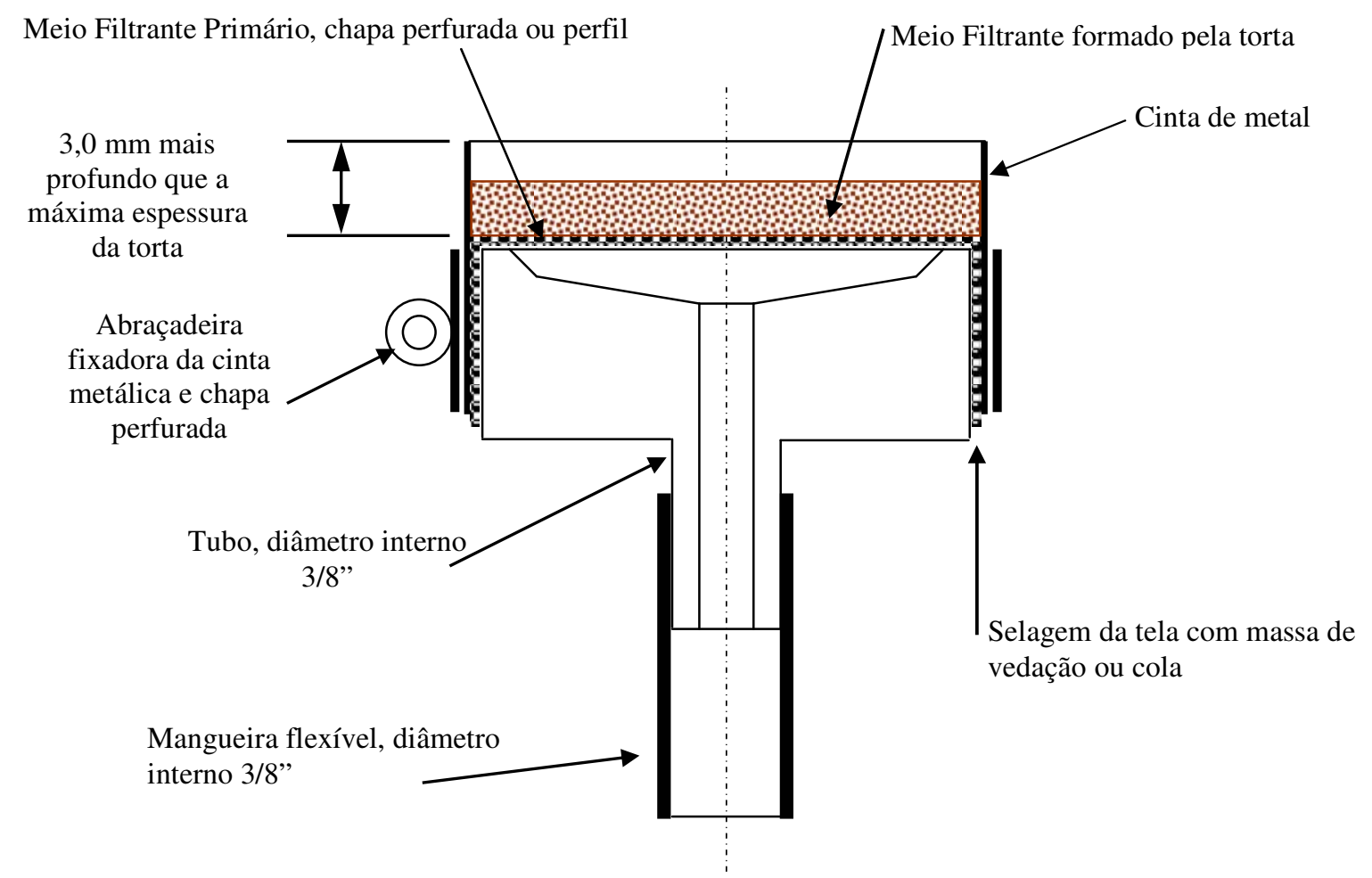

FIGURA 1. Detalhe do dispositivo típico para Teste-Folha ("Filter leaf test").

A profundidade da cunha para a base de alimentação do teste mostra ser não maior que a profundidade da máxima espessura da torta, exceto quando testes de lavagem da torta são realizados. Nesses casos, a profundidade da abraçadeira deve ser 3,0 $\mathrm{mm}$ maior que a máxima espessura esperada da torta. A profundidade excessiva da abraçadeira interfere na agitação do lodo e pode resultar na formação de uma torta não-homogênea. Por outro lado, se a abraçadeira não for utilizada, a camada de torta filtrada se formará antes da margem da folha, assumindo formato que se assemelha a um cogumelo. Quando isso acontece, a área de filtração é um valor desconhecido, diferente da área da folha e constantemente aumentado com o tempo de duração da formação da torta. A montagem do meio filtrante primário onde a abraçadeira sobrepõe, deve ser selada com algum material adequado. O volume de filtrado coletado corretamente representa a solução associada ao depósito de sólidos da torta. 


\section{Detalhe do suporte do dispositivo filtro-teste ou "Filtro-Folha" (Filter leaft test)}

Na Figura 2, mostra-se o dispositivo teste-folha, especialmente projetado com o objetivo de minimizar o "volume morto", obtido quando todo o fluido filtrado é succionado pelas tubulações até o recipiente graduado. Esse possui área útil de filtração equivalente ao diâmetro interno, resultando em área calibrada de $9.290 \mathrm{~mm}^{2}$.

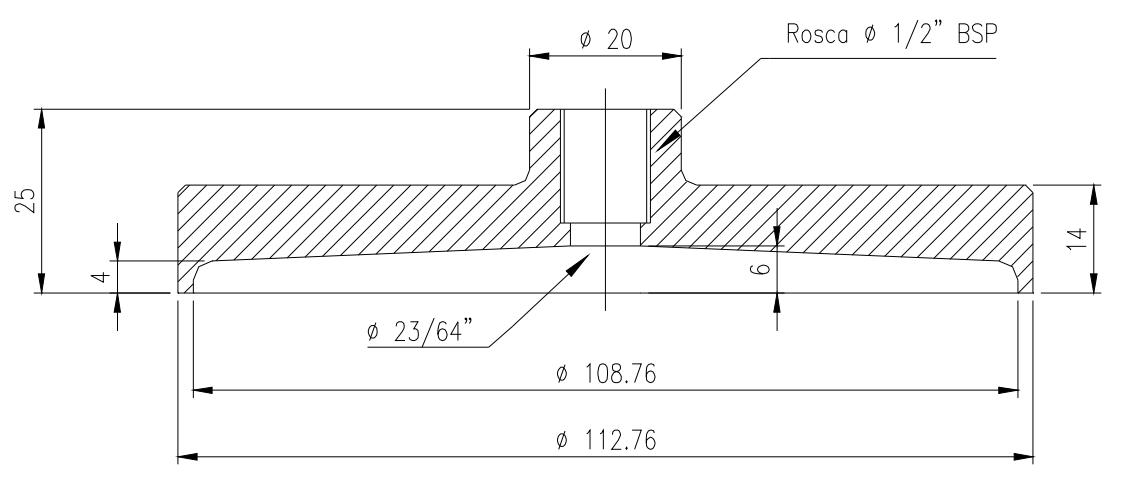

FIGURA 2. Detalhe construtivo do suporte onde é fixado o elemento de filtração primário no dispositivo teste-folha (dimensões em $\mathrm{mm}$ onde não indicado e em polegadas para os furos de passagem de fluido, indicados por (")).

\section{Procedimento para o "Bottom Feed" (alimentação pelo fundo)}

Na Figura 3, acha-se esquematizado o procedimento para coleta de dados, utilizando a técnica de teste-folha "Botton Feed" (alimentação pelo fundo).

Vale ressaltar a inexistência de válvulas na linha de drenagem entre o teste-folha e o recipiente de filtrado, nem entre o recipiente de filtrado e a bomba de vácuo. No início da operação do testefolha, a mangueira entre o teste-folha e o recipiente de filtrado deve ser dobrada manualmente para induzir o recebimento de filtrado para a operação do nível de vácuo.

\section{Verificações básicas para início de funcionamento}

É imperativo que se verifiquem a limpeza do sistema e a inexistência de materiais estranhos depositados no circuito (dispositivo teste-folha, mangueiras, válvulas, recipiente graduado, tubulações, outros) decorrentes do ensaio anterior; a operacionalidade do sistema (válvulas, vacuômetro, reguladores, sistema de vácuo, cronômetro, outros); a estanqueidade das uniões, mangueiras, válvulas, conexões, rolha e engates no recipiente calibrado entre chapa perfurada, dispositivo e abraçadeira; a montagem de todo o sistema, posição do recipiente calibrado, a existência da folha de dados, lápis para anotação e outros.

\section{Instalações e funcionamento da planta-piloto anexa ao filtro rotativo}

Para o desenvolvimento deste trabalho, foi construída e instalada a planta-piloto anexa ao filtro rotativo a vácuo (Figura 4). Três experimentos distintos, com o objetivo de avaliar as variáveis de filtração que se referem ao meio filtrante primário, realizando os ensaios com água, ensaios com lodo adotando variação das condições operacionais, como temperatura, viscosidade e ensaios da filtração de lodo reproduzindo as condições operacionais reais da filtração a vácuo, foram realizados. 


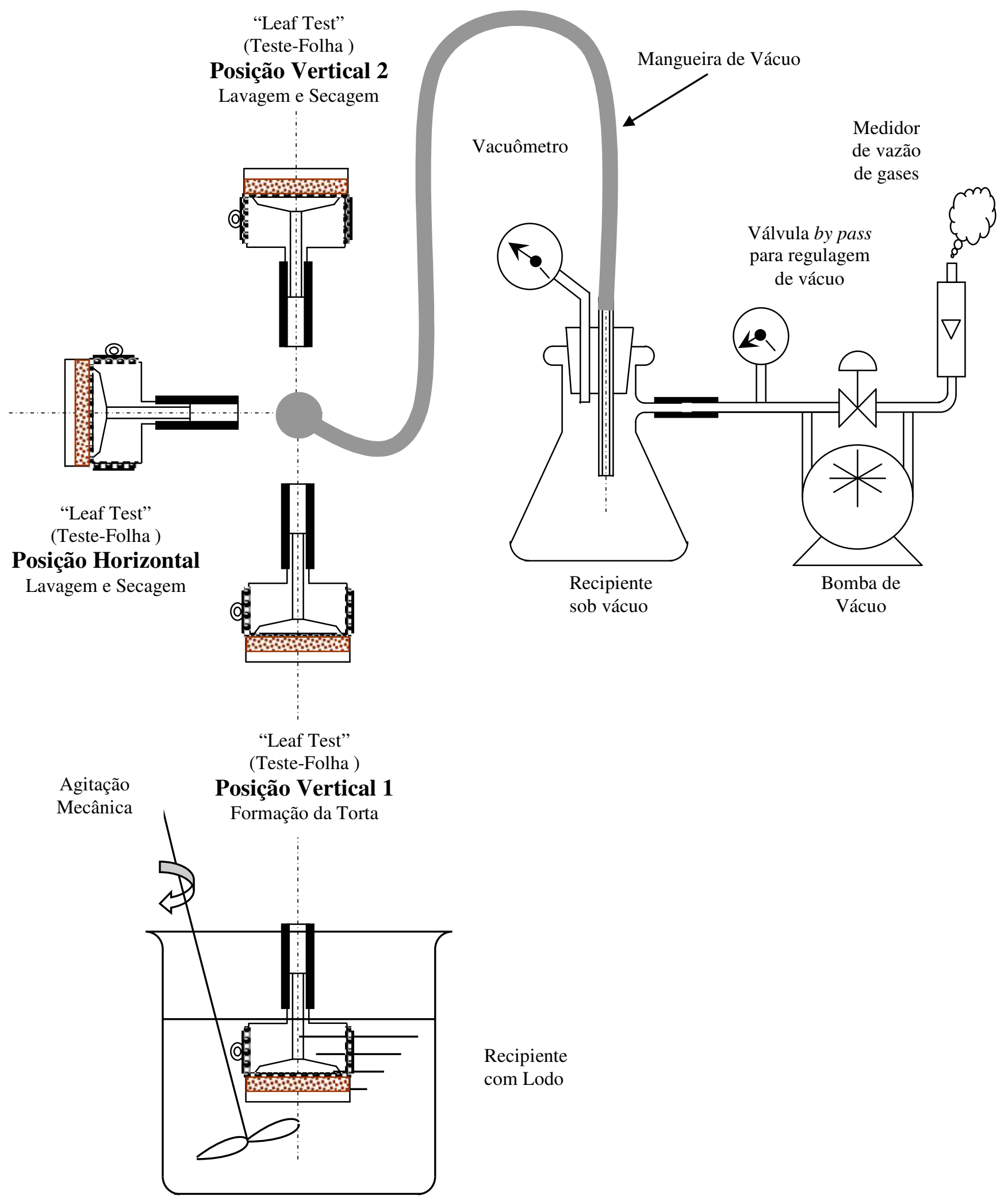

FIGURA 3. Típico arranjo do "Leaf Test" (teste-folha). 


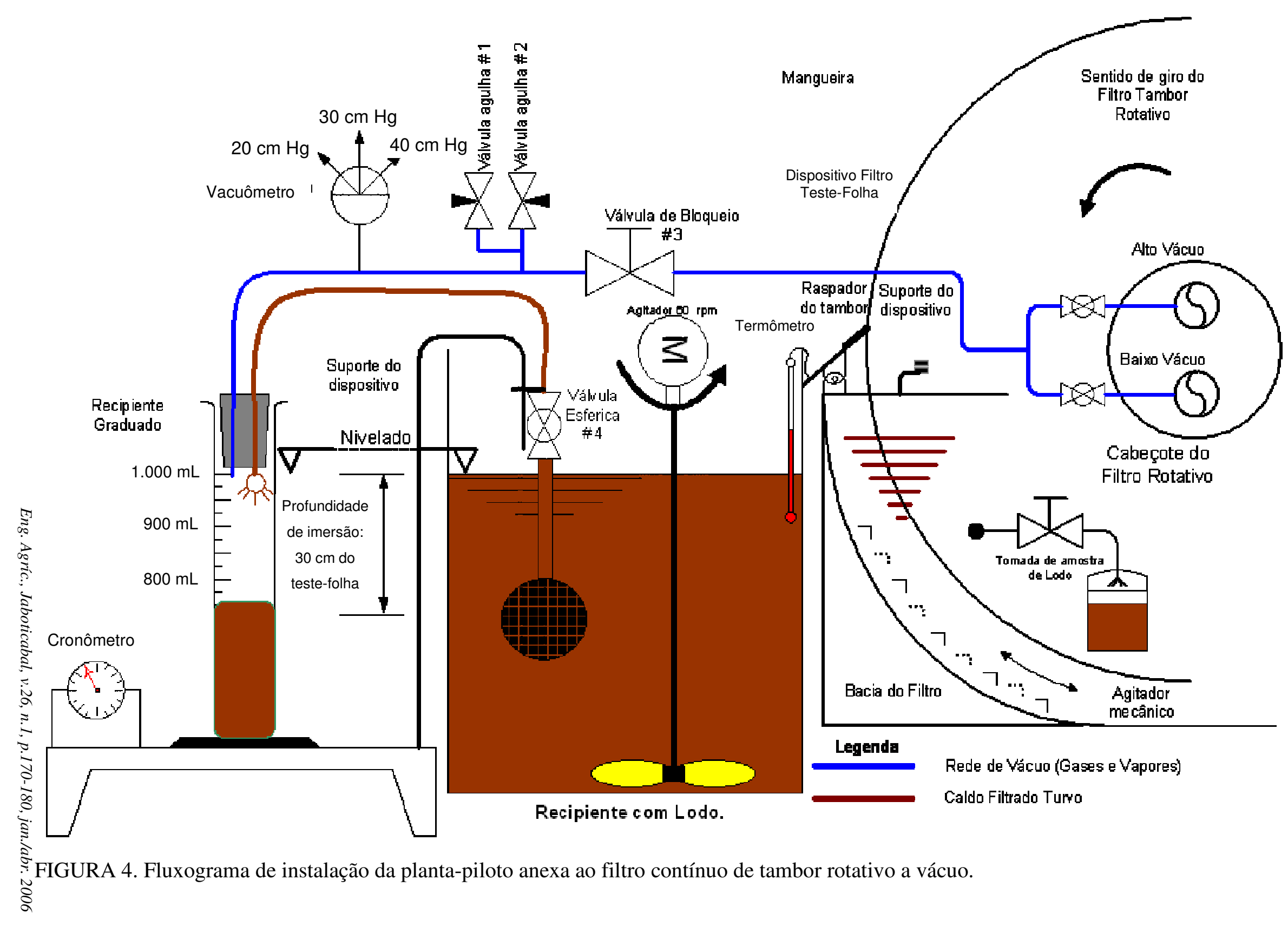




\section{RESULTADOS E DISCUSSÃO}

Pelos resultados obtidos (Figura 5), pode-se observar que ocorre maior taxa de filtração com a utilização da chapa perfurada pelo processo de fotocorrosão química com faces eletropolidas (chapa 11). Mesmo não sendo o meio filtrante primário que possui a maior área aberta, o mesmo possibilitou a obtenção da melhor taxa de filtração. O melhor acabamento superficial do meio filtrante, através do eletropolimento, facilitou o escoamento de filtrado.

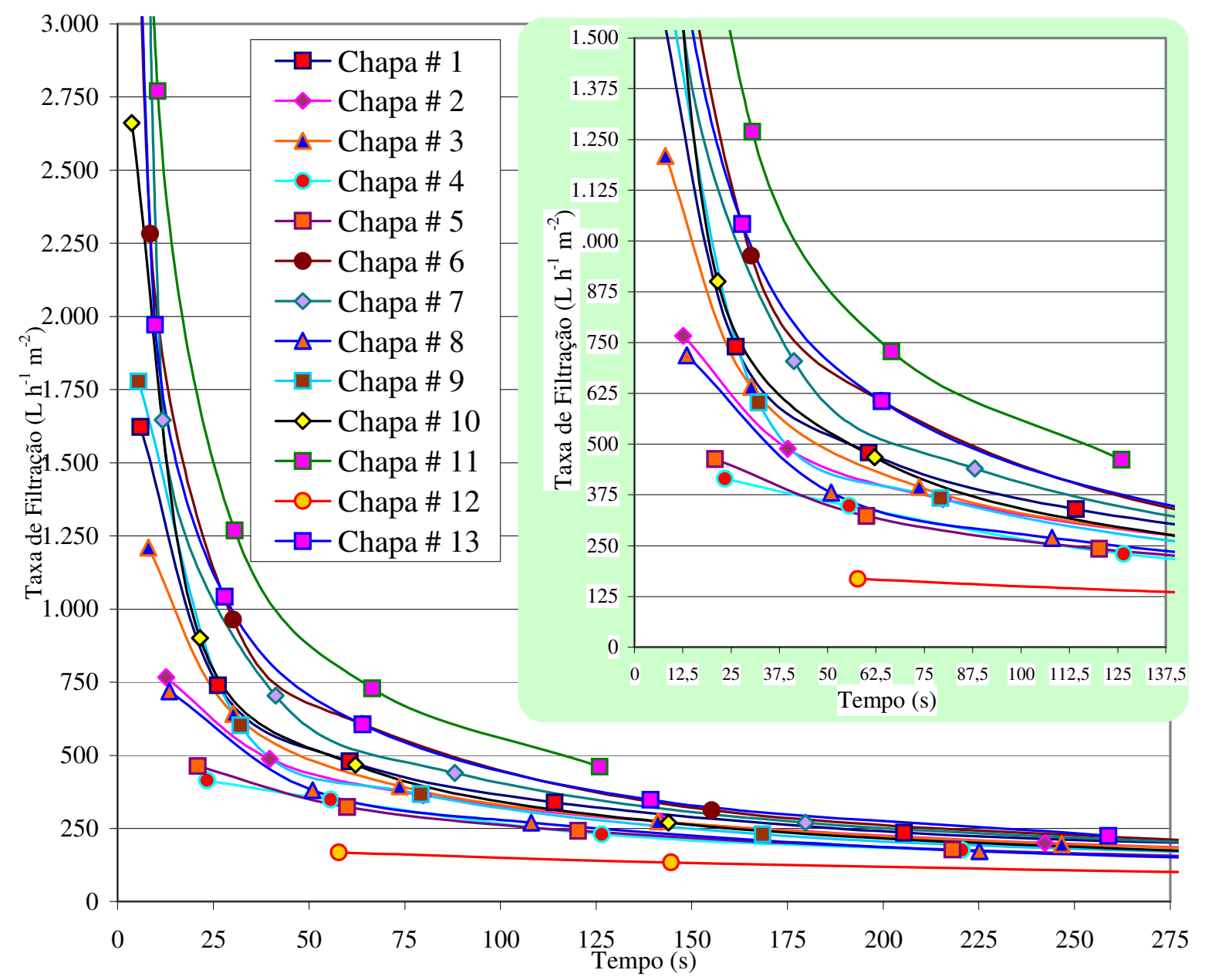

FIGURA 5. Efeito do tipo de meio filtrante na taxa de filtração e tempos finais de filtragem para volume de $150 \mathrm{~mL}$ de filtrado de lodo de caldo de cana (vácuo $26,7 \mathrm{kPa}$, temperatura de $\left.75^{\circ} \mathrm{C}\right)$.

Na Figura 5, pode-se também observar que mesmo meios filtrantes com maior área aberta não tiveram desempenho superior aos resultados obtidos com a chapa 11.

Para o experimento com variação do vácuo, observa-se acentuado aumento da taxa de filtração e diminuição dos tempos de formação e de desidratação da torta, como mostrado na Figura 6.

A linha pontilhada indica a curva de tempo final de formação da torta e a tracejada o tempo de término da desidratação no detalhe. Observa-se que ambas se comportam com decréscimo acentuado de tempo de formação e desidratação com o aumento do vácuo aplicado, ao mesmo tempo em que a taxa de filtração se eleva. 


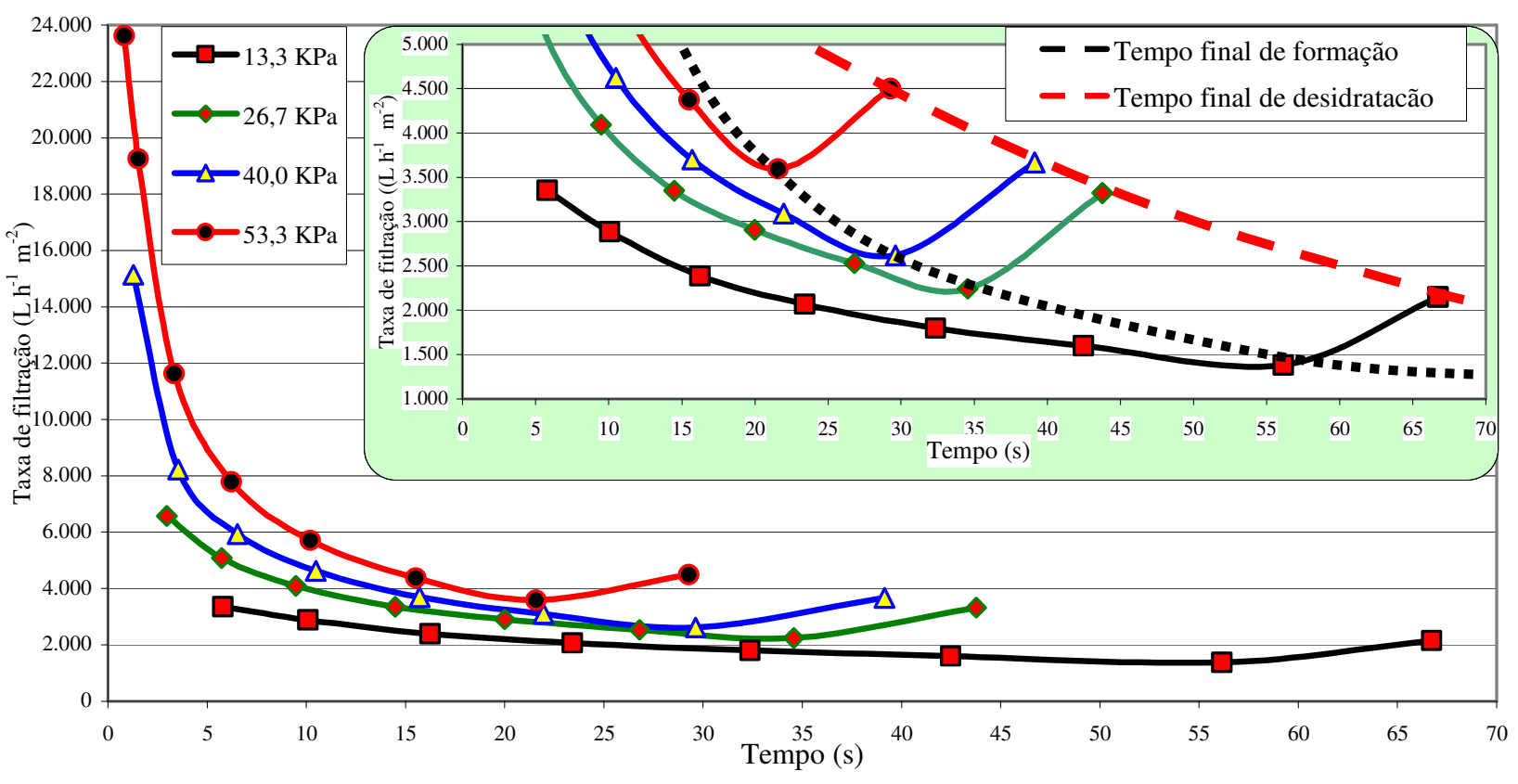

FIGURA 6. Efeito do vácuo aplicado na taxa de filtração e tempos finais de filtração para volume de $200 \mathrm{~mL}$ de filtrado de lodo de caldo de cana à temperatura de $75^{\circ} \mathrm{C}$, chapa 1.

Obtiveram-se os seguintes valores da Tabela 2, utilizando-se de meio filtrante 1, na filtração de lodo de caldo de cana à temperatura de $75^{\circ} \mathrm{C}$.

TABELA 2. Valores médios da taxa de filtração e tempos de formação e desidratação da torta.

\begin{tabular}{cccc}
\hline $\begin{array}{c}\text { Vácuo } \\
(\mathrm{kPa})\end{array}$ & $\begin{array}{c}\text { Taxa Média de Filtração } \\
\left(\mathrm{L} \mathrm{h}^{-1} \mathrm{~m}^{-2}\right)\end{array}$ & $\begin{array}{c}\text { Tempos de Formação da } \\
\text { Torta (s) }\end{array}$ & $\begin{array}{c}\text { Tempos de Desidratação } \\
\text { Final (s) }\end{array}$ \\
\hline 13,3 & 1.380 & 56,16 & 66,72 \\
26,7 & 2.242 & 34,56 & 43,76 \\
40,0 & 2.617 & 29,61 & 39,13 \\
53,3 & 3.593 & 21,57 & 29,28 \\
\hline
\end{tabular}

Observa-se que as diferenças entre os tempos finais de formação e desidratação da torta permanecem estáveis em função do vácuo aplicado, num valor médio de 9,2 segundos. Fisicamente, essa observação indica o tempo correto de início da lavagem da torta, desde o instante em que o tambor do filtro rotativo sai da imersão da bacia de lodo com a torta formada.

Na Figura 7, apresenta-se a quantidade de sólidos passantes no filtrando em função do vácuo aplicado. O resultado do experimento realizado demonstra as influências do vácuo sobre a taxa de filtração. Verifica-se que o aumento crescente da quantidade de sólidos passantes pelo meio filtrante para vácuo, de até $30,0 \mathrm{kPa}$, representa queda de eficiência da filtração, com redução da retenção de sólidos no meio filtrante. 


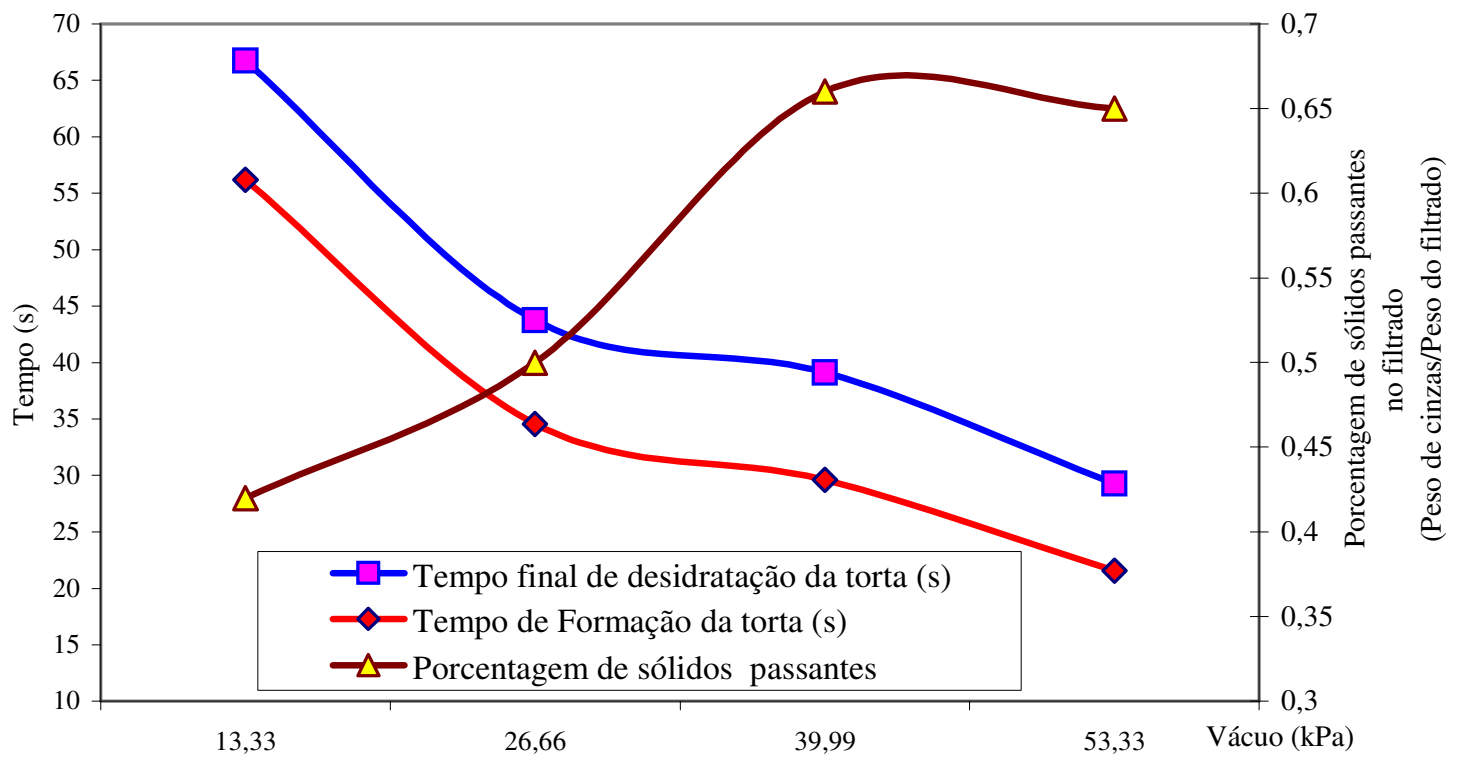

FIGURA 7. Comparativo dos tempos de formação e desidratação da torta mais porcentagem de sólidos passantes no filtrado, em função dos níveis de vácuo aplicados nas etapas de filtração de lodo de caldo de cana à temperatura de $75^{\circ} \mathrm{C}$, para chapa perfurada 1.

\section{Determinação da melhor face para filtração}

O experimento realizado para a determinação da melhor face das chapas perfuradas em contato com a formação da torta tem seus resultados apresentados na Figura 8.

Observam-se as influências do nível de vácuo e do tipo de face mais recomendada onde se deposita a torta de filtração. A face mais recomendada, para o caso de chapas perfuradas mecanicamente, resultou na face lisa. Importante ressaltar que os tempos finais de formação da torta também foram menores para as chapas lisas, devido à menor queda de pressão causada pelo fluxo de caldo filtrado no sentido da expansão da furação, e também pela menor possibilidade de entupimento das furações na face lisa, como mostrado na Figura 8.

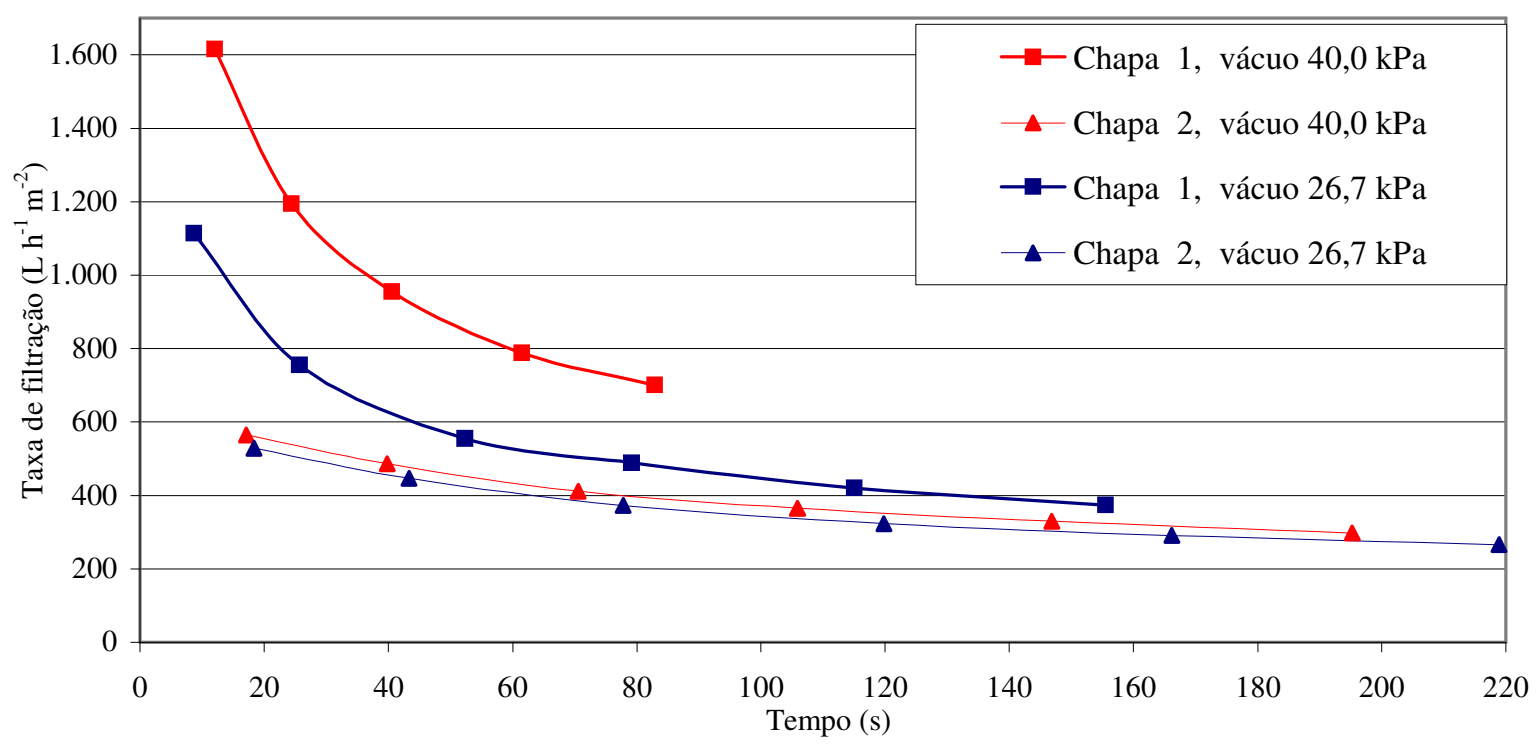

FIGURA 8. Taxas de filtração em função do tempo, comparando as faces lisa e rugosa de chapas perfuradas a vácuo de $26,7 \mathrm{kPa}$ e $40,0 \mathrm{kPa}$ para lodo de caldo de cana, a $75^{\circ} \mathrm{C}$. 
Na Tabela 4, apresentam-se os valores das taxas médias de filtração para o tipo de face avaliada para os meios 1 e 2 , respectivamente, faces lisa e rugosa.

TABELA 4. Valores das taxas médias de filtração e tempos de formação para o tipo da face.

\begin{tabular}{cccccc}
\hline Número & Tipo da & \multicolumn{2}{c}{ Taxa Média de Filtração $\left(\mathrm{L} \mathrm{h}^{-1} \mathrm{~m}^{-2}\right)$} & \multicolumn{2}{c}{ Tempos de Formação da Torta (s) } \\
\cline { 3 - 6 } da Chapa & Face & Vácuo 26,7 kPa & Vácuo 40,0 kPa & Vácuo 26,7 kPa & Vácuo 40,0 kPa \\
\hline Chapa 1 & Lisa & 374 & 701 & 155,52 & 82,9 \\
Chapa 2 & Rugosa & 266 & 298 & 218,92 & 195,24 \\
\hline
\end{tabular}

Na Figura 9, mostra-se esquematicamente a diferença dos perfis entre os tipos de furos obtidos pelo processo mecânico e fotoquimicamente.

(e)

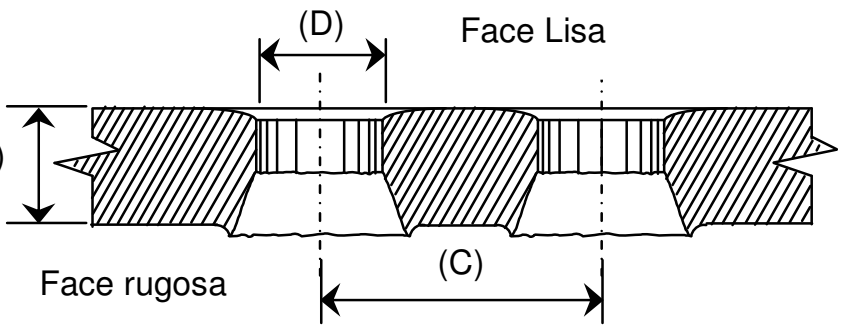

(e)

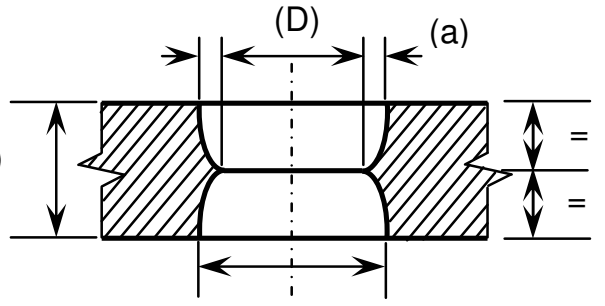

FIGURA 9. Perfil típico de furação das chapas comerciais obtidos pelo processo mecânico (à esquerda) e pelo processo de fotocorrosão química (à direita). (a) espessura da folga entre os diâmetros interno e externo dos furos obtido pelo processo de fotocorrosão química; (C) dimensão de centro a centro entre furos; (D) diâmetro interno dos furos; (e) espessura da chapa perfurada, e (=) simetria ou igualdade de dimensões.

Nas Figuras 10 e 11, apresentam-se as fotos obtidas pelo processo MEV (Microscopia Eletrônica de Varredura), das chapas com furos redondos, processadas mecânica e fotoquimicamente.

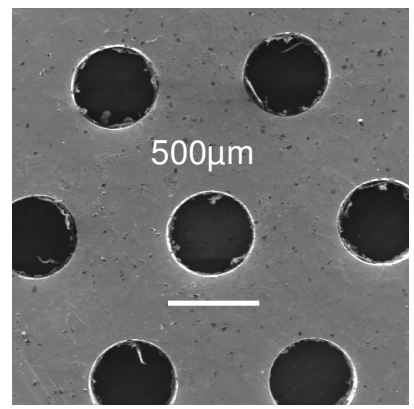

Chapa \# 5 face lisa, $(50 \mathrm{X})$

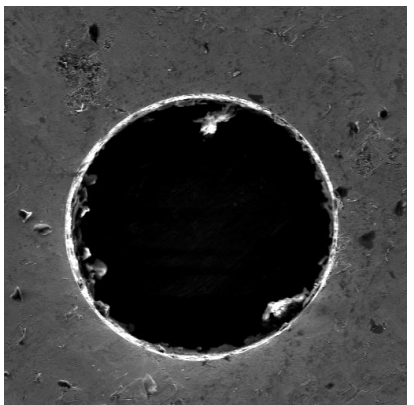

Chapa \# 5 face lisa $150 \mathrm{X}$

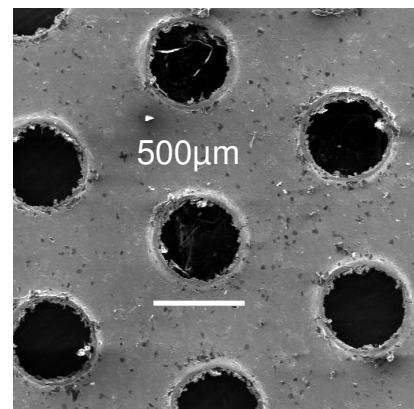

Chapa \# 6

face rugosa $50 \mathrm{X}$

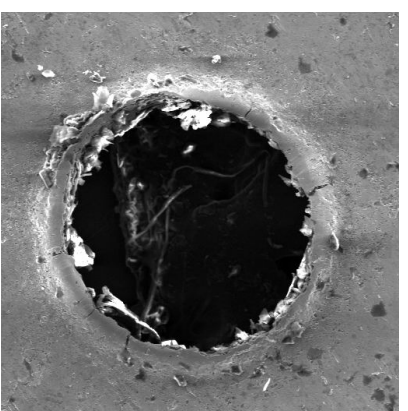

Chapa \# 6

face rugosa $150 \mathrm{X}$

FIGURA 10. Fotos dos meios filtrantes primários 5 e 6 obtidas pelo processo de puncionamento a frio. Detalhes de acabamento do lado liso e lado rugoso, respectivamente. 


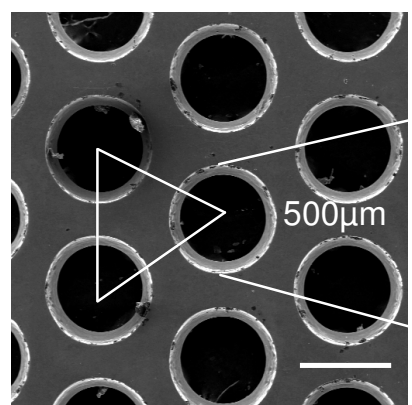

Chapa \# 11, (50 X)

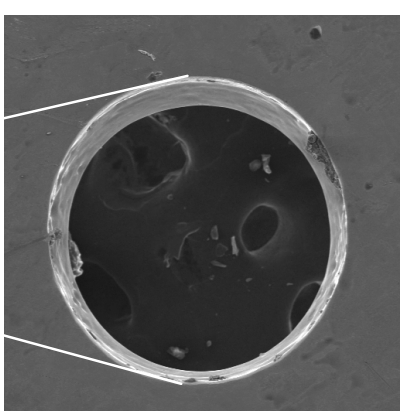

Chapa \# 11, (150 X)

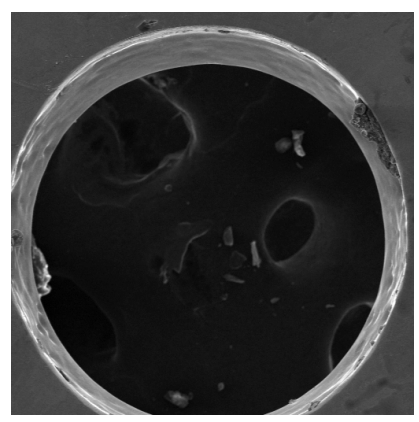

Chapa \# 11, (200 X)

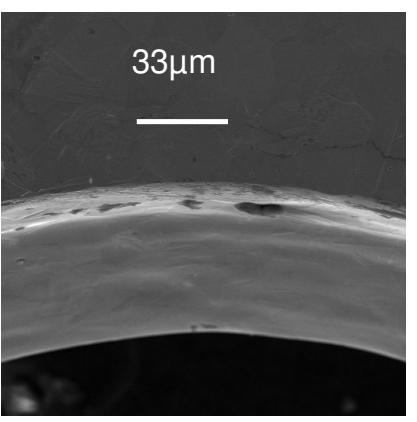

Chapa \# 11, (750 X)

FIGURA 11. Foto da chapa 11, obtida pelo processo de fotocorrosão química. Detalhe do acabamento da furação.

\section{CONCLUSÕES}

Os meios filtrantes primários, formados por chapas perfuradas pelo processo de fotocorrosão química, foram os mais eficientes, em relação aos demais meios filtrantes testados, resultando em aumento na taxa de filtração.

Para o comparativo de meios filtrantes primários, em função do vácuo aplicado, constatam-se aumentos das taxas de filtração e respectiva redução dos tempos de formação da torta em torno de $62 \%$ para vácuos de 13,7 a 26,7 $\mathrm{kPa}$, podendo chegar a 260\% para vácuos passando de 13,7 a 53,3 $\mathrm{kPa}$.

A influência da ação impulsora, representada pelo vácuo, não deve ser analisada somente em relação à taxa de filtração, mas também pela quantidade de sólidos passantes pelo meio filtrante, que também tem seu valor aumentado de forma significativa para valores acima de $26,7 \mathrm{kPa}$.

Para as chapas perfuradas mecanicamente, as faces lisas possuem melhor desempenho em relação à taxa de filtração.

\section{AGRADECIMENTOS}

À Usina da Barra S.A. - Açúcar e Álcool - GRUPO COSAN, pela disponibilidade de suas instalações e laboratórios na realização deste trabalho.

\section{REFERÊNCIAS}

ARQUED, A.P. Fabricación del azucar. Barcelona: Salvat Editores, 1955. 328 p.

CARLETON, A.J.; MACKAY, D.J. Assessment of models for predicting the dewatering of filter cakes by gas blowing. Filtration and Separation, Croydon, v.25, n.3, p.187-91, May/June 1988.

CATANDUVA, A.B.; CIQUEIRA, C. Laranja e gado cedem espaço à cana. O Estado de São Paulo, São Paulo, 26 jun. 1999. Seção Economia, p.B12.

PERRY, R.H.; CHILTON, C.H. Chemical Engineers' Handbook. $5^{\text {th }}$ ed. New York: McGraw-Hill, 1977, p.76. (Liquid - Solid Systems)

PURCHAS, D.B. Cake filtration. A Standard. Chemical Engineering, New York, v.79, n1., p.86-93, 1972.

SPENCER, E.F.; MEADE, G.P. Manual del azucar de caña. Tradução de M.G. Menocal. Barcelona: Montaner y Simon, 1967. cap. 11. 1.204 p.

WAKEMAN, R.J. Filtration and washing on vacuum filters - Process optimization for economy.

Proceedings of the Filtration Society, Filtration and Separation, Austrália, v.21, n.1, p.201-6, May/June 1984. 